\title{
The evolution of Biophysical Reviews
}

\author{
Cristobal G. dos Remedios ${ }^{1}$
}

Received: 17 December 2015 / Accepted: 18 December 2015 /Published online: 15 January 2016

(C) International Union for Pure and Applied Biophysics (IUPAB) and Springer-Verlag Berlin Heidelberg 2016

The Biophysical Reviews journal was created in the Spring of 2009 as an equal partnership between the International Union for Pure and Applied Biophysics (IUPAB) and the publisher, Springer (Heidelberg). It replaced Quarterly Reviews of Biophysics as the official journal of the IUPAB.

Biophysics is sometimes described as the research that biophysicists do, but, more precisely, it can be defined as the science of examining biological phenomena using the concepts and techniques of physics. In particular, the new journal covers focussed reviews on topics in medical biophysics, biosystems biophysics, cell biophysics, molecular and macromolecular (proteins, DNA-RNA) biophysics, single-molecule biophysics, nanobiophysics, bioinformatics and computational biophysics. In practice, Biophysical Reviews publishes on biomembranes (ion channels, membrane receptors, membrane transport systems, membrane lipids), molecular motors (muscle contraction, cell motility), protein/lipid/nucleic acid structure and function. The 'A' in IUPAB stands for "Applied", and, so, biophysics is also concerned with the application of discoveries in biophysics to medicine and biology.

With the retirement of the inaugural Editor-in-Chief, Dr. Jean Garnier (now Editor Emeritus) in March 2015, I was

Cristobal G. dos Remedios crisdos@anatomy.usyd.edu.au

1 Discipline of Anatomy and Histology, The University of Sydney, Sydney, Australia appointed by the Executive of the IUPAB as Editor-in-Chief. As a Professor Emeritus in the Faculty of Medicine, an honorary Professor in Physics in the Faculty of Science, both at the University of Sydney, and as the current Secretary-General of the IUPAB, I bring over 45 years of research experience and have authored more than 250 publications and published four books by Springer Press. I agreed to take on the position for six years (pictured below).

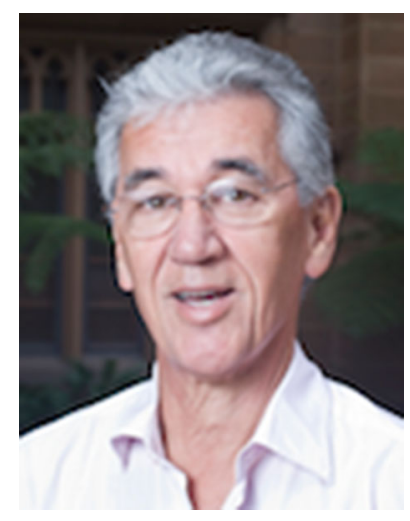

I began by re-organising the Editorial Board. I replaced the four former Associate Editors with five Executive Editors, whose functions include: identifying and inviting expert authors in the various fields covered by biophysics, arranging for timely reviews of their manuscripts and executing the decision on whether the reviews submitted to them should be published. Their geographic distribution (USA, Wilma Olson; Japan, Haruki Nakamura; India, N.R. Jagannathan; Australia, Damien Hall (pictured left below); and The Netherlands, 
Jolanda van der Velden) was in keeping with the international nature of the IUPAB. The composition and functions of the general Editorial Board was also modified.

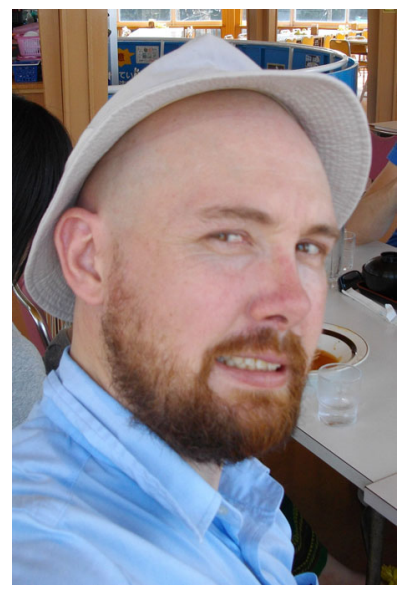

In 2012, Professor Haruki Nakamura and I trialled the first Special Issue (dos Remedios and Nakamura 2012). We explored the research opportunities offered by computational biophysics in developing economies, reasoning that the Internet is ubiquitous and that mathematics and computation is an innate human characteristic present in all cultures and societies. We assembled a group of mentors with access to the necessary computing power (Wriggers et al. 2012), and we solicited reviews covering the theory, methods (molecular dynamics, modelling) and systems of computational biophysics (Ho 2012), and showed how these could be harnessed via the Cloud.

The next year, I helped Damien Hall (Hall and dos Remedios 2013) to assemble an issue filled with tributes to Allen Minton on the event of his 70th birthday. Allen is described as the most innovative biophysicist of the last 50 years (Hall and dos Remedios 2013). The issue was the largest ever assembled in Biophysical Reviews and included 17 reviews on the theme protein-ligand Interactions. Damien, who is now an Executive Editor, is pictured on the above.

In 2014, Marcelo M. Morales (now President-Elect of IUPAB) assembled 14 contributions that paid tribute to the success of biophysics in Latin America (Morales and Alonso 2014), including a contribution from the eminent Venezuelan biophysicist, Carlo Caputo (Calderón et al. 2014). It also saluted the establishment of the Latin American Federation of Biophysical Societies (LAFeBS),

By the beginning of 2015, there were signs that Special Issues were attracting more citations than the regular reviews. This is understandable when one considers that readers who are interested in a focussed topic such as human heart failure are more likely to find, read and cite a paper from a Special Issue. The citation rates for the 2013 Special Issue described above were pleasingly high, so I decided that Special Issues should become a permanent feature of the journal. This also required also some re-organising of the old Editorial Board, the members of which were selected on the basis of their ability to assess a wide range of contributions in biophysics. It also demanded a new category of editor whose sole task was to edit one Special Issue over a two-year period. Thus, a regular feature of Biophysical Reviews from 2015 onwards will be the creation of two Special Issues each year.

Thus, in 2015, issue 1 of volume 7 was devoted to Special Issue 1 titled Biophysics of Human Heart Failure, co-edited by Amy Li (pictured right below) and myself ( $\mathrm{Li}$ and dos Remedios 2015). The contributors were united by the fact that all of them had performed research on failing and non-failing human heart samples from the Sydney Heart Bank (see Li et al. 2013). The contributors were 'lured' to a conference on Heron Island, Queensland, one of two true coral islands on the Great Barrier Reef. For many of them, this was the first time they had physically met and been able to discuss results from heart samples from the same patients.

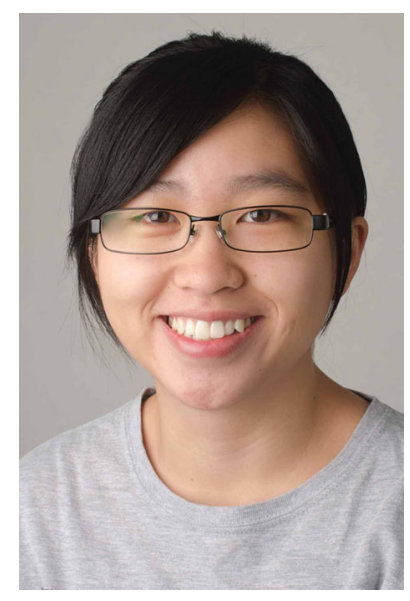

Issue 2 of volume 7 was also a Special Issue, edited by Professor Gordon Roberts, who assembled reviews in The Role of Protein Dynamics in Allosteric Effects. This issue focussed on the concept that a ligand interacting with one site on a protein can change the functional properties at another site without direct spatial proximity of the two binding sites (Roberts 2015).

This year, in volume 8, two Special Issues are scheduled. Laura Finzi at Emory University (pictured first below) has teamed up with Wilma Olson at Rutgers (pictured second below) to produce a Special Issue (issue 3 volume 8 ) on Supercoiling in DNA-Protein Interactions. The next issue (issue 4 volume 8) will be edited by Damien Hall (pictured above) at the Australian National University, now a 'veteran' Executive Editor of Biophysical Reviews. The focus of this Special Issue is on Analytical Solutions to Problems in the 
Field of Quantitative Biochemistry. It will honour the work of Donald J. Winzor.
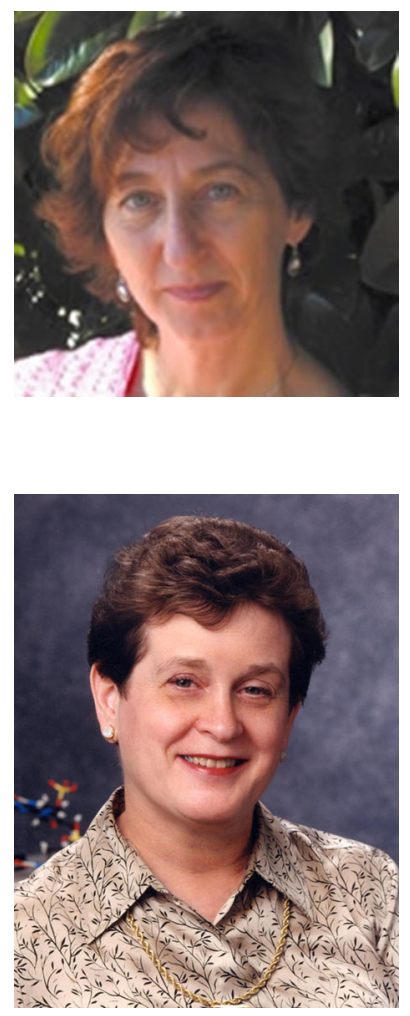

After that, other Special Issues are planned, one on Nanobiophysics and another on The Giant Protein Titin and its Binding Partners.

Finally, but certainly not least, in 2015, it was announced that Springer Press, the publisher of Biophysical Reviews, underwent a major change. The consortium that owns Springer Science+Business Media has acquired the majority of Macmillan Science and Education to form a powerful new entity called Springer Nature. This strategic acquisition produced a company with almost 13,000 staff publishing in over 50 countries, with a turnover of 1.5 billion Euros. Its combined expertise and enhanced scale and distribution bodes well for the continuing success of Biophysical Reviews.

Cris dos Remedios
Editor-in-Chief
Biophysical Reviews
Springer Nature

\section{References}

Calderón JC, Bolaños P, Caputo C (2014) The excitation-contraction coupling mechanism in skeletal muscle. Biophys Rev 6:133-160

dos Remedios CG, Nakamura H (2012) Editorial. Biophys Rev 4:149151

Hall D, dos Remedios CG (2013) Foreword to the biophysics of proteinprotein and protein-ligand interactions in dilute and crowded media - a special issue in honor of Allen Minton's 70th birthday. Biophys Rev 5:57-60

Ho JWK (2012) Application of a systems approach to study developmental gene regulation. Biophys Rev 4:245-253

Li A, dos Remedios CG (2015) Special Issue on human heart failure. Biophys Rev 7:1-3

Li A, Estigoy C, Raftery M, Cameron D, Odeberg J, Pontén F, Lal S, dos Remedios CG (2013) Heart research advances using database search engines, Human Protein Atlas and the Sydney Heart Bank. Heart Lung Circ 22:819-826

Morales MM, Alonso S del V (2014) Successful Katin American initiatives in biophysics. Biophys Rev 6:1-3

Roberts G (2015) The role of protein dynamics in allosteric effectsintroduction. Biophys Rev 7:161-163

Wriggers W, Olson WK, dos Remedios CG (2012) Computational opportunities for remote collaboration and capacity building afforded by Web 2.0 and cloud computing. Biophys Rev 4: $153-160$ 